\title{
How Infertility Patients and Providers View and Confront Religious and Spiritual Issues
}

\author{
Robert Klitzman ${ }^{1}$
}

Published online: 30 November 2017

(C) Springer Science+Business Media, LLC, part of Springer Nature 2017

\begin{abstract}
Questions arise concerning whether and how religion affects infertility treatment decisions. Thirty-seven infertility providers and patients were interviewed. Patients confront religious, spiritual, and metaphysical issues coping with treatment failures and religious opposition from clergy and others. Religion can provide meaning and support, but poses questions and objections that patients may try to avoid or negotiate-e.g., concealing treatment or changing clergy. Differences exist within and between religions. Whether and how much providers discuss these issues with patients varies. These data, the first to examine several key aspects of how infertility providers and patients confront religious/ spiritual issues, have important implications for practice, research, guidelines, and education.
\end{abstract}

Keywords IVF · Ethics · Gamete donation · Religion · Clergy

\section{Introduction}

Religious beliefs can play critical roles in patients' decisions about terminating pregnancies, but many questions arise concerning how, when, and to what extent these beliefs may affect patients' and providers' views and decisions regarding infertility treatment. Assisted reproductive technologies (ARTs) have been spreading, with $10 \%$ of couples infertile (Chandra et al. 2013). Additionally, many women are delaying childbirth to pursue careers, but then have fertility problems (Gleicher et al. 2014). Gaymen, lesbians, and single individuals are also having children using ART (Marina et al. 2010). Yet the success rate for any one in vitro fertilization (IVF) cycle is only approximately 40\% (RESOLVE 2016). Hence, many patients struggle with ongoing treatment failures and inabilities to have children, which can be very stressful (Peterson et al. 2007).

Robert Klitzman

rlk2@cumc.columbia.edu

1 Columbia University, 1051 Riverside Drive; Mail Unit \#15, New York, NY 10032, USA 
Infertile patients in various cultures may invoke spiritual and religious notions (Greil et al. 1989), which can help in coping with stresses of infertility and finding meaning as part of holistic care (Roudsari et al. 2007). Spiritual well-being has been correlated with lower depression and psychological stress (Chan et al. 2012; Domar et al. 2005; Sewpaul 1999).

Leaders in several religions, including Christianity, Protestantism, Judaism, and Islam, have strong views about aspects of reproduction-especially abortion and acceptability of various ARTs (Schenker 2005). Religion may influence choices of ARTs (Braverman and Corson 1995; Inhorn 2006; Isikoglu et al. 2006; Klein 2013), particularly in third-party reproduction. Klein (2013) argued that donor eggs and embryos may be the interventions most affected by religious objections and that ART providers should become aware of the religious issues that may emerge. Among male patients surveyed at an infertility practice and an OB/GYN practice, $75 \%$ of Jewish participants would opt for donor gametes versus only 5\% of Catholics and 46\% of Protestants (Braverman and Corson 1995).

Religious and spiritual beliefs also affect gynecological oncologists: $45 \%$ think that their own religious/spiritual beliefs play a role in their medical decisions, $87 \%$ consider patients' religious/spiritual beliefs when discussing end-of-life issues, $68 \%$ feel their own spiritual/religious beliefs help them in death with feelings about death, and $62 \%$ feel that their own spiritual religious beliefs are a source of comfort to them as oncologists (Ramondetta et al. 2011). OB/GYNs were more likely to object to contraceptive methods if they attended religious services twice a month or more, thought religion was very or more important (vs. not or fairly important), and were Catholics and Evangelical Protestants (Lawrence et al. 2011).

Generally, women in conservative religions that promulgate traditional gender roles (e.g., Orthodox Judaism), given restrictions, often "negotiate" their way in religious communities, actively constructing roles for themselves within religious and cultural contexts, and frequently remaining ambivalent (Avishai 2008). Such women may adopt approaches of resistance, empowerment (reinterpretation of religious doctrine), instrumentalism (using religious interpretation to achieve other ends in their lives), or compliance (Burke 2012).

As ARTs continue to advance and spread, many questions thus arise regarding how patients and providers view, respond, and make decisions, given potential religious objections-whether they accept, resist, or respond in other ways to these potential impediments, and if so, how.

Thus, as part of a study of how clinicians and patients perceive, experience, and make decisions concerning several critical aspects of infertility treatments, these issues were explored.

\section{Methods}

In brief, as described elsewhere (Klitzman 2016a, b, c, d, e, f, 2017) and summarized in Table 1, 37 in-depth semi-structured telephone interviews of approximately $1 \mathrm{~h}$ each were conducted with 27 ART providers - 17 physicians (MDs) and 10 other providers (OPs) (7 mental health providers, 2 nurses, and 1 other) — and 10 patients (PTs). One physician and three other providers were also themselves patients. Patients and providers were recruited through Listservs, e-mails, and word of mouth. Providers were recruited, too, through national American Society of Reproductive Medicine (ASRM) meetings (e.g., 
Table 1 Characteristics of sample

\begin{tabular}{lrcr}
\hline & Male & Female & Total \\
\hline Physicians & 14 & 3 & 17 \\
Physicians who are also patients & 0 & 1 & 1 \\
Type of practice & & & \\
$\quad$ University affiliated & 5 & 1 & 6 \\
$\quad$ Private practice & 9 & 2 & 11 \\
Other art providers & 1 & 9 & 10 \\
(e.g., mental health providers, nurses) & & & \\
Other providers who are also patients & 0 & 3 & 3 \\
Patients & 1 & 9 & 10 \\
Total & 16 & 21 & 37 \\
\hline
\end{tabular}

preimplantation genetic diagnosis [PGD] and mental health provider interest group meetings). A mental health Listserv was used, which is received by approximately 60 members (not all of whom are active), of whom 15 responded, and 8 were then interviewed. Interviews were conducted with each group until "saturation" was reached (Guest et al. 2006). Interviewees were from throughout the USA. Among the patients, six worked full-time, one worked part-time, two were graduate students, and one was unemployed. Their ages ranged from 25 to 48 (mean 36.1). Most of the patients had been undergoing a few years of infertility treatment and were at various stages of treatment, having thus far tried several interventions, seeking first or second children.

Interviews explored participants' views and decisions regarding ethical issues concerning several aspects of ART and were systematically analyzed to obtain detailed descriptions of these issues. From a theoretical standpoint, Geertz (1973) has advocated trying to understand individuals' own experiences, drawing on their own words and perspectives to obtain a "thick description." The methods adapted elements from "Grounded Theory" (Strauss and Corbin 1990).

The questionnaire was drafted, drawing on the prior literature.

Sample questions for providers included:

- What challenges do you face in your work as an ART provider? How do you address the challenges?

- Have religious or spiritual issues arisen in your treatment of patients? If so, when and how? What happened?

- How do you view these issues?

- How have your patients confronted, viewed, or made decisions about these issues?

- What additional thoughts do you have about these issues?

Sample questions for patients included:

- What challenges have you faced concerning ARTs? How did you address these?

- What factors influenced your decisions?

- With whom have you spoken concerning your decisions about infertility treatment?

- Some people's decisions are affected by their religious or spiritual views. Has that been the case for you? If so, how?

- Do you have other thoughts about these issues? 
Providers described interactions with many patients they had treated and with colleagues. Patients often described interactions with multiple providers and other patients. Transcriptions and initial analyses of interviews were carried out during the period in which the interviews were being conducted, enhancing validity, and helped shape subsequent interviews. Interviews were conducted via phone. The Columbia University Department of Psychiatry Institutional Review Board approved the study, and all participants were sent an information sheet and gave verbal consent.

Analyses were conducted primarily by trained research assistants (RAs) and the principal investigator (PI), who read each interview, systematically coding blocks of text to assign "core" codes or categories (e.g., religious objections arising concerning ART use; input from clergy in decision-making about ARTs; and physician and patients responding to religious issues concerning ARTs) and developed a coding manual.

They then independently content-analyzed the data to identify the principal subcategories and ranges of variation within each of the core codes. Subcategories included, e.g., religious objections to sperm collection, pregnancy reduction, use of donor gametes, and other specific procedures; patients not disclosing ART use to potential social supports due to fears of religious objections; and patients changing clergy due to religious objections to ART. Codes and subcodes were then used in analysis of all of the interviews.

\section{Results}

Overall, as outlined in Fig. 1 and described more fully below, in grappling with infertility, many patients invoke religion and spirituality in various ways. Patients confront not only religious, but related spiritual and metaphysical issues concerning both coping with failures
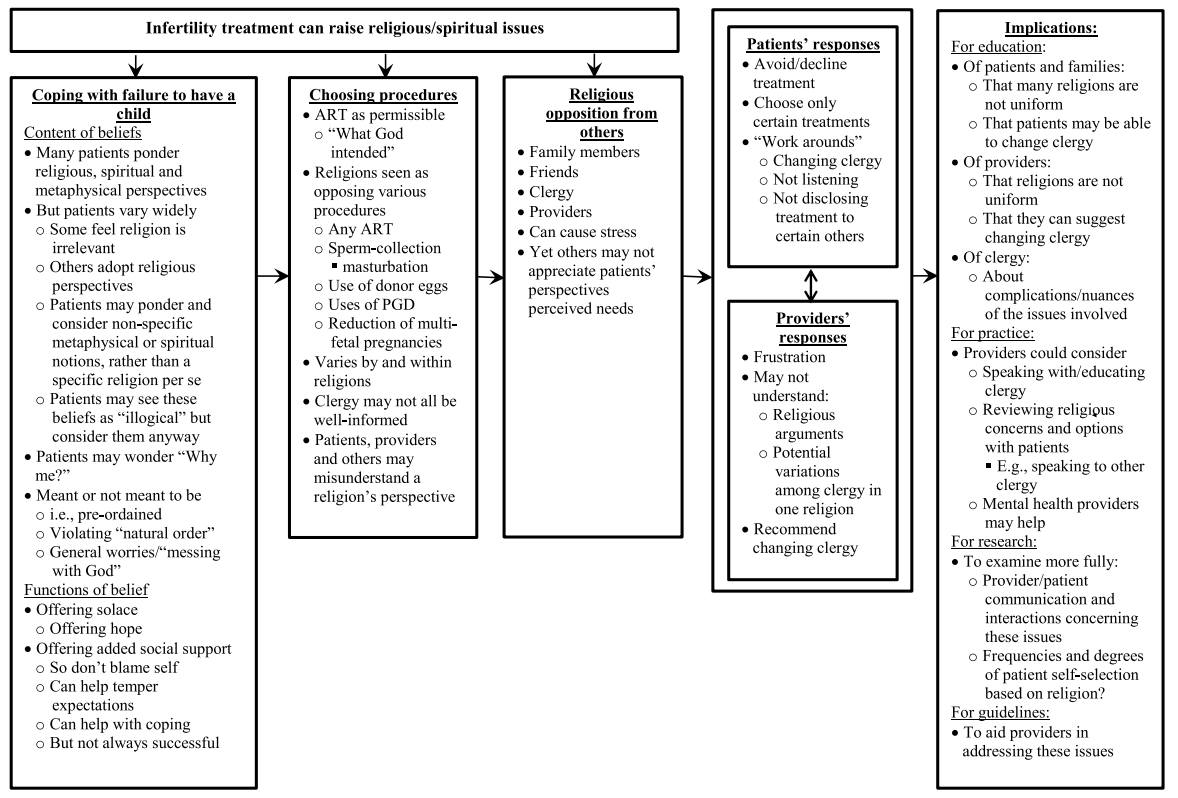

Fig. 1 Themes concerning how infertility patients and providers view and confront religious and spiritual issues 
to have a child and with religious opposition to the use of certain ARTs. Religious notions can provide order, solace, and social support, but also impede treatment. Patients may confront religious objections in themselves or in family members or friends. Certain religious leaders and communities question or oppose ART in ways that frustrate and limit patients. Yet these objections may be viewed differently between and within religions, and may be decreasing among some groups over time. Patients may follow these prohibitions, change clergy, or proceed with treatment, at times keeping it secret. A few phrases are underlined for emphasis.

\section{Religion in Coping}

In grappling with and trying to make sense of ongoing failures to have a child, patients vary widely from rejecting to pondering to adopting religious perspectives. One group of patients felt adamantly that the causes of infertilty are not metaphysical, but simply biological, even if unknown.

Religion has nothing to do with whether or not I'm able to have a baby. I ended up with infertility; my sister ended up with cancer. Neither are ideal. It's probably due to something in our environment. There's nothing that I could have done. I had endometriosis from age 13. I don't feel any self-blame. Things just happened for me when I was ready for them to happen. They happened when they happened for a reason - because I wasn't ready at another time to explore those options." [PT\#8]

Yet many other patients ponder or adopt religious perspectives in various ways. Patients may invoke religion in seeking solace and/or assessing why they are infertile, what treatments they should or should not choose, and how they should cope with continued failures.

Religions can relieve the burden of responsibility that patients may feel for ongoing childlessness.

I try to console my wife, telling her "it will happen. You just have to have a little faith." I believe things happen for a purpose and are pre-written. I really do. My pastor just brings it back to being in God's hands. [PT\#2]

Involvement with religious organizations can thus provide helpful social support. "Our parish priest used to come once or twice a week. It was good to have somebody there." [PT\#3]

\section{Why me?: Metaphysical Notions of Fate and Explanation}

Many patients, struggling unsuccessfully to have a child, wonder more broadly, "Why me?"-feeling that their failure is unfair and seeking some explanation. To cope, many,

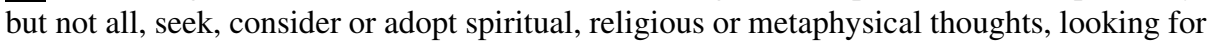
explanations-something to blame, even if they realize these searchers are not logical.

Patients often ponder metaphysical notions of fate or karma - that having children is or is not somehow "meant to be" - as fated or not. Patients may struggle with these metaphysical questions, uncertain what to believe. They may recognize that such feelings are not "logical," but nonetheless consider these notions, including broader metaphysical ideas about cosmological order or fairness. 
There was a soul-searching point: What did I do in my life to deserve this? I don't have a relationship with my mother, so I wondered if karma came back to bite me. My husband has had a lot of health problems so we waited "til the right time, and I thought, "Maybe that was it: We passed our window of opportunity." Logically, I knew that there was none of that. I have endometriosis, so that was a contributing factor. So logically I knew, but emotionally, there's a whole process - I wanted something, someone, some reason to blame. I searched for what brought this upon me. Some days, I figured maybe it was God not wanting it to happen. At moments I was definitely ticked at God and thought: "Just let it happen, it would be easier on both of us!"...I prayed, begged, pleaded, tried not praying - the whole spectrum. But mostly I kept in perspective: Maybe my body was just not able to. [PT\#5]

These religious and spiritual beliefs can widely. Many of these men and women did not follow any one particular established religion per se, but rather considered or pondered more non-specific spiritual or metaphysical notions, drawing on wider beliefs about the world. As this patient continued,

I like the tradition of religion, but don't necessarily believe in religion. I believe in God. But if there is one God, there would be one religion, and no matter what religion you are, it should be a unifying factor amongst people, not a divisive factor. [PT\#5]

As they struggle on arduous journeys to have a child, many patients grapple to make sense of these complex, uncontrollable processes, impeding their hopes and dreams, and look for "signs" or "omens" — either good or bad. This patient added, for instance:

Three eggs fertilized well. We were going to put in all three, but the day of the transfer, the embryologist suggested that one wasn't strong. I took it as a sign, or interpreted it as, "These two have a good shot. If you add the third, it might not work. So just stick with the two. This is what was meant to be!" [PT\#5]

Conversely, in wrestling with ongoing failures, patients may believe that having a child was simply not "meant to be," suggesting a metaphysical sense of fate and outcomes being preordained. As this patient explained, "Because of the failed attempts through the IUIs, by the time we got to IVF, I just felt that maybe it wasn't meant to happen ... I started thinking, 'maybe my body isn't meant to have a child." " [PT\#5]

These beliefs can have added psychological functions. As this patient continued, "As a protective measure for myself: if I didn't think it would work, I wouldn't be disappointed when it didn't. I tried that strategy, but it wasn't successful." [PT\#5]

Metaphysical beliefs can thus abet psychological coping, and help avoid or temper over-expectations. Patients may seek to adopt the attitude that success is not "meant to be." If one expects failure, one won't be as disappointed.

Yet these questions of whether persistent treatment failures indicate that having a child was not "meant to be" can potentially affect treatment decisions. Patients may be unsure how to deal with these notions and possibilities-how much to challenge them and/or nonetheless to pursue additional treatment, especially at significant financial cost. As this patient added, "so deciding whether I wanted to go through one more procedure in order to try and carry a child was really difficult." [PT\#5]

These notions may not be tied to particular religious traditions, but rather reflect nonspecific metaphysical beliefs concerning fate and a sense of purpose in the universe, related to notions of cosmic justice, but separate from religion per se. "I'm not a very religious 
person. I just take life as it comes. If it's meant to be, it's meant to be. If it's going to happen, it will happen." [PT\#6] Yet, who or what is predetermining these outcomes is often unclear. Still, many patients feel that their infertility is unfair, and wondered "why me," though usually concluding that God did not will it:

I don't believe that God wanted this - because there is no reason for it. It's definitely unfair and stinks. Why does it happen to certain people? I don't know. I don't think anyone does. But I went through all those emotions. [PT\#9]

\section{Religion in Choosing Procedures}

Religious and metaphysical beliefs can shape several sets of decisions, including whether and which patients end up pursuing infertility treatment, and which and how many procedures. Patients as well as their family, friends, and clergy may feel strongly that religious beliefs preclude the use of certain fertility treatments. Certain religious leaders permit a few, but prohibit other procedures. Yet within any one religion, a wide range of views exist.

On the one hand, patients may have strong religious values but see IVF as consistentas fulfilling what God would have wanted. Patients may see IVF as "natural." ("IVF is a nice, clean procedure, and is just doing what God intended. I'd definitely recommend it to anybody who wants to have a child." [PT\#2])

The patient above who wondered if having a child was "not meant to be" was undecided whether to undergo additional treatment. Yet other patients confront stronger religious objections either to ARTs as a whole or to specific procedures, and at times never even try to obtain any infertility treatment, self-selecting out of ART. "Religious views affect patients a lot. But a lot of that we'll never see in the clinic. They take themselves out and don't set foot here." [OP\#3]

Patients who in fact consult ART clinics may generally have come to terms with these potential qualms. Many patients who pursue ART may seek ways to overcome these potential religious objections.

In general, religious issues don't come up. The patients we see figure out a way to work around them, whether it's that they're not supposed to do IVF, or whatever. It's sad when people whom we know we could help don't pursue ARTs for religious reasons. [MD\#9]

Some clinicians may not commonly see certain patients with extreme religious views, but nonetheless still observe a variety of religious attitudes among their patients. Providers were thus generally acutely aware, through the media and elsewhere, of religious objections to various ART treatments that exist among certain groups in broader society, even if seldom encountering these obstacles in their clinical practice. Patients and/or their clergy may feel that only relative "low-tech" procedures are acceptable religiously, guiding decisions about what treatments, if any, to pursue-even if the resulting limited range of procedures is ineffective.

Extremely religious Jews have to talk to the rabbi about everything. Their rabbis will say, "No, you can't do this." The couple will have a diagnosis, but the rabbi will only let them do low-tech interventions. The doctor's hands are tied by the rabbi and the belief system. You watch the couple go through disappointment after disappointment. It's not our place to tell them they should believe or do something else. [OP\#6] 
Religious leaders may oppose a variety of aspects of ART from large to small, often depending on the specific details involved.

Some Catholics, when told they need IVF, will say, "I'm sorry, we can't do that." Many Muslims don't use donor eggs. Rabbis may also say "No" to a particular treatment, though the couple would benefit - donor eggs for instance. [OP\#6]

Due to religious concerns, patients may not want to end up creating extra, unused embryos. But physicians then face dilemmas, since the number of embryos that a woman will need to produce a child cannot be known in advance. "Occasionally, patients want us to limit the amount of eggs we fertilize because 'life begins with fertilization.'” [MD\#11] Clergy may disagree with providers' recommendations concerning whether and how much reduction of pregnancies can occur. As one provider reported, for instance, one rabbi permitted a woman pregnant with quadruplets to reduce to three-instead of only one or two fetuses.

I feel horrible about one case. She transferred three embryos. I did not discourage her. She got pregnant with four; one was twins. The rabbi said he will only allow reduction to three. Are triplets a good outcome? No. She's now at 14 weeks. She's going to have a tough pregnancy and need a lot of help, they felt that they don't have options: Orthodox, and knowing that they will not do an abortion, or their rabbi told them, "I won't allow it." [OP\#1]

PGD appealed as an option to many patients at risk of genetic disease who opposed abortion. Many Orthodox Jewish patients, in particular, appeared to like the notion of PGD, though other religions oppose it.

\section{Disagreements Within Religions}

Within a particular religious tradition, leaders may disagree in their views of various ART procedures. In part, the moral considerations in various procedures can vary. Clergy can disagree on not only abortion, but amniocentesis, PGD, and specific procedures or aspects of ARTs. Certain rabbis may, for instance, oppose IVF and PGD since they object to sperm collection through masturbation.

Rabbis did not permit IVF when it came out. Some rabbis still don't agree. How does the husband produce and bring the sperm? Is he allowed to produce sperm that way? Most IVF centers allow men to bring it in a special condom that doesn't have spermicide. But some rabbis don't allow that kind of condom. One prominent rabbi will not allow it if the couple is fertile. He allows it with a condom if someone is infertile, whose only option to have kids is through IVF. But for PGD, the issue is sick kids, not just kids. Thank God, we figured out different ways to get sperm - by retrieving it from the woman a half-hour later. If there's a life-threatening illness, most rabbis will agree to do PGD, but what if the couple has four kids already? Should they do PGD, or not have any more kids? [OP\#1]

A key decision may thus be with which particular member of the clergy a patient consults.

One rabbi can tell you: chorionic villus sampling [CVS], followed by abortion, is okay. For the same couple, the other rabbi would tell you: do only PGD or do nothing 
- rely on God. So the issue is which rabbi they're going to choose. Once they decide the rabbi, they'll definitely listen to him. [OP\#1]

Yet, given these variations, patients, providers, family members, and others may misunderstand a religion's perspectives, and make incorrect assumptions about its views.

There's a lot of misinformation on what you could do. Most people assume that in Judaism, you could not do CVS and an abortion for anything, even for Tay-Sachs that the fetus is human life, even before 40 days. But many rabbis will allow you to abort a Tay-Sachs child. Other rabbis say you have to do PGD, then CVS. PGD is such a blessing. [OP\#1]

Rabbis may also differ on which specific potential uses of PGD are acceptable-even for medical conditions - and the relative undesirability of varying severe diseases.

Which is worse? Fragile X or Tay-Sachs? Most rabbis say the baby suffers and dies it's very bad. But one rabbi believes differently: with Tay-Sachs, suffering ends fairly quickly. It's very sad. But with Fragile X, the child and the family suffer for years and years. How do you measure suffering? There are different opinions. I don't think there will ever be a ruling where everyone will agree. [OP\#1]

\section{Religious Opposition from Others}

Religious objections to plans for infertility treatment may arise not from patients or even clergy, but from others-including family and co-workers. Religious objections can be hard to counter partly since friends and family may strongly support these prohibitions, and pressure patients to do so as well. Patients may hence have to grapple with these issues in communities and cultures in which religion plays strong roles. Pursuing treatment despite such opposition can require considerable determination. As one patient said,

People are ignorant about IVF. The religious ones feel you're messing with God. The practical ones say, "Why are you putting yourself through that?" Those who want children, but don't have them, support you 100\%: "Go for it." They're your backbone. The ignorant ones just open their mouth and diarrhea flows out. They're just out of control. When I had my first IVF, my boss was so excited, but was also a religious freak: "Don't you feel that you're tampering with what God didn't want you to do?" I said, "I'm not very religious. If there's a God, there's a God. This is my body; this is what I want. I will do what it takes to get what I want." She just looked at me and said, "But you're tampering with what God wants!" I said, "If God wanted me to not have a child, believe me, He'd let me know." She said, "Don't you see this is His way?" I said, "No. His way would make me sterile. If He wanted me to not have a child, he would have made me sterile. He wouldn't have given me any ovaries." [PT\#6]

Even non-specific metaphysical notions about whether having children was "meant to be" or not could prove double-edged swords, leading patients or their friends or family to argue against using ART, since if God intended children, they would be born.

People have told me, "If God wanted it to happen, it would happen. It's God's way. If you're meant to get pregnant, you'll get pregnant. I thought, "You're going to say that to me right now?" They would also say, "If it was meant to happen, it would happen on its own, without any kind of assistance." If I got pregnant, "that was great 
- meant to be." But if I wanted a child and was not getting pregnant on my own:

"you should adopt or not have children." Some people just believe what's meant to happen is meant to happen - don't mess with it. [PT\#5]

Such comments from others can trigger patients' anger and resentment.

Clergy may disagree partly because they are not always well informed or do not "fully understand" all the medical issues involved. Consequently, patients may end up frustrated, having to make decisions or choose or reject treatments that may put themselves or their future children at risk.

One couple went to a rabbi who was very uninformed and uneducated. They had a child die from spinal muscular atrophy, and the rabbi said, "Do nothing. I'm not allowing you to do anything." The couple listened. They have a healthy child, but I don't think it was a smart gamble. [OP\#1]

Clergy may give ill-informed advice that is not always in the patients' best interest:

Some regular OB/GYNs and midwives say to Orthodox patients, "We want to do the Ashkenazi panel of genetic mutations that are common among Ashkenazi Jews." The patient says, "I don't know what that is. I'm calling my rabbi." The rabbi says,

"Don't do it. How is it going to help you?" [OP\#1]

Religion can thus foster misconceptions and stigma, and impede patients' treatment.

\section{Patients' Responses to Religious Opposition}

Patients respond to religious objections in several ways-from following to avoiding prohibitions. Even individuals who describe themselves as members of a particular religion do not always follow its doctrines and/or may disagree on use of ARTs. Many patients may wrestle with religious qualms or possible objections, but ultimately decide to proceed with treatment. "We've had Catholics and rabbis. Somehow, people do things privately that they don't talk about." [MD\#11]

Patients may pursue treatment, but simply not tell family members, friends, or others who might oppose it on religious grounds. "A lot of couples do it anyway, and don't tell anybody." [OP\#6] These patients may have to weigh their religious qualms against their strong wish to have a child. Their desire for offspring may win, and they may then make the difficult decision to keep the treatment secret within their social network. Religious views can thus impede disclosures about ART use.

When patients are going through it, they've somehow made peace with the religious or ethical conflicts for themselves, because they just want to have a baby. Some have religious conflicts, and are not necessarily telling their families what they're doing, because they expect they'll be censured. [OP\#4]

Yet given these conflicts, patients may also vary in their treatment choices over time, following, rejecting or compromising regarding possible religious objections, weighing religious against other, medical, social, and psychological factors-not only religious beliefs but rates of medical and personal treatment successes and failures. Given the odds and gambles on both sides, patients may fluctuate back and forth over time.

More patients do CVS than PGD. People have done CVS successfully, and did not need to abort. Once they needed to abort, they come back to PGD. Couples have tried 
PGD twice unsuccessfully, and then said, "We've have enough of this, we'll go to CVS." [OP\#1]

\section{Clinicians' Responses to Religious Opposition}

Providers may feel frustrated and be unsure how to interact with patients' clergy and beliefs, especially given that the clergy member-not the doctor or the patient-may determine how the patient will proceed.

For physicians, it's challenging because they don't know how to advise patients. It becomes frustrating when the patient says, "I'm going to the rabbi who will make a decision for me." A doctor should give patients all the options and let them decide. Usually, the patients decide. [OP\#1]

Many geneticists and genetic counselors may need to become more aware of particular issues in certain religious communities. Referring to many patients within the Orthodox Jewish community, one interviewee felt that, generally, geneticists and genetic counselors, "have to understand that the rabbi is going to make the decision, and there's nothing you can do about it. Some geneticists and genetic counselors get frustrated" [OP\#1]. At the same time, this interviewee described discrepancies between rabbis in this community. Clergy within one religion may thus disagree, confusing or frustrating clinicians who are trying to treat the patient.

It's a challenge because doctors ask, "How can it be that this rabbi allows this, and that rabbi does not? How can it be that this rabbi says, "Don't do any testing, it's a dominant disease, it's going to kill your family. No one is going to marry your family. It's going to be the curse of your life," and the other rabbi says, "Do it, it's only $50 \%$. If she's not a carrier, it's good." [OP\#1]

\section{Recommending Consultations with Other Clergy}

Given variations among religious leaders, knowledgeable providers may in fact suggest that patients seek and consult with other, more supportive clergy. "Couples will be savvy enough to go 'rabbi shopping,' to get one to say 'Yes.' We have our list of rabbis, and say, 'Why don't you consult with Rabbi so-and-so?'” [OP\#6]

Clinicians may also try to educate and inform patients about details of procedures and options in ways that may sway treatment decisions, with patients who, because of religious objections, do not want to end up with unused embryos:

If patients are young, we'll go ahead and try to educate them. If they're older, we choose not to treat them, or do a minimal stimulation. Because they're going to affect our results. In the handful of cases I've been able to do it because the patients were really young and have acceptable pregnancy rates. If they're older and mature, it's not in their best interest. I drag my feet. I imagine they go elsewhere. [MD\#11]

A physician may thus delay treatment because of treatment decisions patients may make based on religious views, hoping the patient will instead seek care from a different provider, but ethical concerns then emerge. 


\section{Conclusions}

These data, the first to examine several critical aspects of how IVF providers and patients view and confront religious and spiritual issues that arise in infertility treatment, suggest that these issues can play a wide range of key roles. These beliefs can help patients cope with ongoing failures to have children, but also affect whether patients pursue infertility treatment at all, and if so, which procedures. Patients may confront religious objections not only from clergy, but family members, friends, and others, and then have to determine how best to respond. Many patients "work around" such real or potential objections, and/or pursue treatment secretly. Providers vary in whether and how they discuss these issues with patients, and at times may suggest that patients consult with more sympathetic clergy. Religious and spiritual views thus emerge as double-sided coins that can potentially help patients cope, but also limit treatment options and thus outcomes, potentially impeding treatments in ways with which providers and patients may then wrestle.

These data suggest several phenomena that have not been reported in the prior literature. First, while the past literature has suggested that infertility patients may invoke spiritual and religious notions (Greil et al. 1989; Roudsari et al. 2007), and face religious objections to infertility treatment, the present data offer elaborations in several key ways-e.g., by suggesting how a broad range exists of several specific typologies, views, and responses, and how patients may adopt various strategies, either accepting, rejecting, negotiating, or 'working around' these beliefs. This finding is indeed consistent with research on how women in traditional religions, generally-not specifically in relation to ART-may negotiate, rather than simply accept all religious structures (Park 2005).

Secondly, the current data suggest that patients may have to confront and address religious objections from not only themselves and clergy, but friends and family. Thirdly, the current data suggest that the availability and use of new technologies can pose challenges for not only patients, but providers as well, who may then be unsure how to respond, and may fail to understand religious objections, and be unsure about their own roles. Fourthly, while the past literature has focused on the impact of organized religions, the present data highlight how broader metaphysical beliefs (e.g., concerning cosmic "fate") that are not explicitly tied to a religion may have key roles - thus including patients who may not see and describe themselves as following a particular religion. Hence, future studies should explore and assess not just patients' membership in major religions, but these broader sets of beliefs as well. Fifthly, while prior data suggest that clergy may oppose ARTs, these data suggest that clergy may in fact misunderstand these treatments, highlighting needs for education of clergy about these issues. Sixthly, these data suggest that patients may consequently adopt several strategies, including pursuing, but not disclosing treatment to others. Yet, concealment of treatment may cause other strains, impeding social support. Seventhly, while the prior empirical literature has suggested that religion may most affect third-party reproduction (Klein 2013), the current data underscore how religion may shape views and approaches toward other ARTs as well, including PGD and CVS followed by abortion. Eighthly, while prior studies on ARTs have tended to explore the effect of religion on either psychological well-being among patients (Domar et al. 2005; Sewpaul 1999) or treatment choices (Braverman and Corson 1995), the present data suggest that religion can shape views of both infertility symptoms and ART treatment-and that complex processes may be involved, with many patients struggling to decide whether to let religion influence their choices, and if so, how, which, and to what degree. Many patients come to draw on religious, spiritual, and metaphysical notions to 
help them cope, but reject or "work around" beliefs that might impede treatment optionspicking and choosing various aspects of religion. These data thus highlight how future empirical studies covering ARTs should examine these two sets of issues together rather than separately.

These data from providers and patients are closely linked in several critical ways. While each patient may generally be aware of only his or her own religious views, the providers here had each worked very closely with hundreds, if not thousands, of patients over several years, observing and getting to know them, including key aspects of their religious, spiritual, and metaphysical views, beliefs and questions. Yet within each of these two groups (i.e., patients and providers), wide variations exist. Each group can range considerably in its religious, spiritual, and metaphysical views and attitudes. As indicated, these providers also come from across the USA and have a range of professional backgrounds (e.g., physicians, mental health providers, or nurses). Some providers may never see certain patients with extreme religious views, but nonetheless do still see many others.

Though, as one interviewee said in referring to some Orthodox Jewish patients, "there is nothing you can do about it," providers can do much for many other patients. The wide range of religious, spiritual, and metaphysical views as well as of types of infertility treatment (from medications, IVF, and PGD to eliminating transmission of certain fatal or other conditions) makes it hard to generalize across all patients and providers. Rather, these data highlight the wide range of views between patients and providers. These views often play critical roles in treatment decisions but in differing ways, with different degrees of flexibility versus firmness.

The report of the doctor who "drag[ged] his feet" with older ART patients raises several ethical concerns, including the risk of misleading patients, of wasting patients' time and, in certain cases, exposing them to risks of hormonal stimulation (albeit "minimal") with low likelihood of benefit. Many IVF clinics are very entrepreneurial, and motivated by statistics that they report to the Center for Disease Control and Prevention and Society for Assisted Reproductive Technology, raising ethical questions (Speier 2011). For instance, providers face key decisions regarding how many embryos to transfer, since professional guidelines often contain ambiguities and are unenforced. Doctors may thus transfer additional embryos due to their own competing motives to increase reported success rates (Williams et al. 2015; Klitzman 2016c). ASRM guidelines say about "fertility treatment when the prognosis is very poor or futile" that "care should not be provided solely for the financial benefit of the provider or center" (Ethics Committee 2012). But concerns emerge, too, regarding doctors motivated "largely" or "at all" by profit. Hence, in this guidance statement, the term "solely" should be deleted. The present data thus underscore needs for stronger professional guidelines, and potential oversight and better monitoring.

These findings have important implications for education of patients, family members, clergy, and providers. Clergy, who end up making these decisions for many patients, may not fully understand the procedures, trade-offs, and issues involved. Religious leaders and adherents may interpret religious doctrines as applying to ARTs in differing ways that can leave room for wide variations. Indeed, the Bible, the Koran, and other traditional religious texts, all written thousands of years ago, do not explicitly address ARTs. Consequently, religious perspectives on ARTs interpret and extrapolate from ancient documents that may not readily apply. In many religions, debates about abortion may also form a highly charged backdrop against which controversies about ART occur, potentially obscuring relevant differences and distinctions. Differences within one religion have been noted in applications of doctrines to other areas of medicine (e.g., definitions of brain death) (Miller et al. 2014), but the present data suggest such differences in infertility treatment as well. 
For instance, clergy who oppose certain ARTs may nonetheless feel that other infertility treatments are acceptable. Yet patients may not realize that within their faith tradition, clergy can differ in beliefs regarding the permissibility of various ARTs. Providers, too, may not all realize that clergy within a particular religion may vary in perspectives and that referrals to more sympathetic clergy may be possible. Some patients may end up simply not pursuing treatment, but countless other patients and providers operate in largely secular worlds in which increased awareness and education concerning the diversity and possible alternative interpretations of religious doctrines may prove beneficial. Indeed, the present data suggest that "rabbi shopping" (or the equivalent in other religions) may aid patients.

Nurses and mental health providers can play helpful roles here and should be as aware as possible that uneasiness about religious views can impede treatment, in part due to misunderstandings about religious views and treatment options. These providers can also aid patients in confronting questions of "why me?" and whether childlessness is "meant to be." Similar religious and metaphysical questions arise with patients coming with other medical problems as well, but may take on particular forms with infertility, given the larger metaphysical dimensions of bringing a life into the world. Providers should be as aware and sensitive as possible about these concerns.

These data also have vital implications for practice, highlighting needs for a variety of clinicians, including OB/GYNs, pediatricians (who may treat children with inheritable conditions that patients could potentially avoid transmitting to future children through PGD), infertility physicians and nurses, mental health providers and others to be aware of the full range of these issues, and possibilities of educating patients about the whole array of available options. Questions also emerge concerning the roles of providers-whether they should raise or discuss these issues with patients. Providers should clearly not tell patients what to believe, but clinicians and their patients may benefit from awareness of potential 'workarounds' and of relatively newer technologies such as PGD.

These data also generate additional research questions that can be investigated more fully in future studies using larger samples-e.g., regarding how often and when religious views affect infertile patients' treatment decisions; how often patients pursue treatment despite religious objections; which specific religions and procedures are involved; how often patients encounter religious objections from family members, friends, or clergy, and do not disclose ART use due to fears of religious objection, and whether such secrecy hampers patients' coping; how often providers are aware of, or discuss religious obstacles with patients, and respond to these challenges (e.g., how often they suggest that patients consult with other clergy); and whether and how mental health providers or others assist patients struggling with religious opposition.

Professional organizations could consider offering detailed recommendations and guidelines to help providers and patients address these challenges-e.g., highlighting how patients may benefit from awareness that within any one religion, various clergy may indeed interpret and apply religious doctrines differently concerning ART use.

These data have several potential limitations. Clinicians' perspectives of their patients' thoughts may differ from these patients' actual attitudes, but these providers are very experienced, and have interacted closely with many patients over several years, developing important insights about these prospective parents. Patients' own observations here also appear generally to corroborate these clinicians' perceptions. The sample size is sufficient for qualitative research designed to elucidate the issues and themes that emerge; however, future studies using larger samples are needed to analyze statistically how various groups may differ (e.g., physicians of different religious backgrounds). The present study was designed to investigate underlying concepts, patterns, relationships and tensions 
previously unexamined, rather than trying to quantify or definitively determine the effects of individual variables (e.g., socioeconomic status, age, education, marital status, gender, ethnicity, treatment experiences and type and extent of current religion, and religion of family origin). However, future research, examining these issues on larger numbers of patients and providers, can explore these issues quantitatively to determine whether such variables affect these views and behaviors, and if so, how. Strikingly, such research has not yet been conducted, but the present data can help, adding to the literature in critical ways, as indicated above, suggesting underlying patterns, articulating and framing critical questions for further investigations, highlighting the need for such data, and providing a research agenda. During the course of these interviews, providers did not describe the religious characteristics of each of the hundreds to thousands of patients they had treated, but future investigations can explore aspects of these varied issues further. These interviewees worked in the USA, but extensive literature searches indicate a lack of data addressing these questions in other countries. Similar issues presumably arise in other countries, too, and can be investigated in future studies topics. These data appear to have, however, a certain face validity, illuminating challenges that many patients and providers confront.

In short, these data, the first to explore several key aspects of how religious, spiritual, and metaphysical issues can arise and affect infertility treatment, have important implications for education, research, practice and guidelines.

Acknowledgements The author would like to thank Daniel Marcus-Toll and Bela Fishbeyn for their assistance with data analysis, and Kristina Khanh-Thy Hosi, Sarah Kiskadden-Bechtel, Charlene R. Sathi, Alexa Woodward and especially Patricia Contino for their assistance with the preparation of the manuscript.

Funding The research supported by Grant Number UL1 RR024156 from the National Center for Research Resources (NCRR), the Greenwall Foundation, and the John Simon Memorial Guggenheim Foundation.

\section{Compliance with Ethical Standards}

Conflict of interest Dr. Klitzman has no conflict of interests to declare.

Ethical Approval All procedures performed in studies involving human participants were in accordance with the ethical standards of the institutional and/or national research committee and with the 1964 Helsinki Declaration and its later amendments or comparable ethical standards.

Informed Consent All participants were sent an information sheet and gave verbal consent, which the PI documented.

\section{References}

Avishai, O. (2008). "Doing religion" in a secular world: Women in conservative religions and the question of agency. Gender \& Society, 22(4), 409-433. https://doi.org/10.1177/0891243208321019.

Braverman, A. M., \& Corson, S. L. (1995). Factors related to preferences in gamete donor sources. Fertility and Sterility, 63(3), 543-549.

Burke, K. C. (2012). Women's agency in gender-traditional religions: A review of four approaches. Sociology Compass, 6(2), 122-133. https://doi.org/10.1111/j.1751-9020.2011.00439.x.

Chan, C. H., Chan, C. L., Ng, E. H., Ho, P. C., Chan, T. H., Lee, G. L., et al. (2012). incorporating spirituality in psychosocial group intervention for women undergoing in vitro fertilization: A prospective randomized controlled study. Psychology and Psychotherapy: Theory, Research and Practice, 85(4), 356-373. https://doi.org/10.1111/j.2044-8341.2011.02040.x. 
Chandra, A., Copen, C. E., \& Stephen, E. H. (2013). Infertility and impaired fecundity in the United States, 1982-2010: Data from the National Survey of Family Growth. National Health Statistics Reports, 67(67), 1-19.

Domar, A. D., Penzias, A., Dusek, J. A., Magna, A., Merarim, D., Nielsen, B., et al. (2005). The stress and distress of infertility: Does religion help women cope? Sexuality, Reproduction and Menopause, 3(2), 45-51. https://doi.org/10.1016/j.sram.2005.09.007.

Ethics Committee of the American Society of Reproductive Medicine. (2012). Fertility treatment when the prognosis is very poor or futile: a committee opinion. Fertility and Sterility, 98(1), e6-e9. https://doi. org/10.1016/j.fertnstert.2012.03.045.

Geertz, C. (1973). The interpretation of cultures: Selected essays. New York: Basic Books.

Gleicher, N., Kushnir, V. A., Weghofer, A., \& Barad, D. H. (2014). The "graying” of infertility services: An impending revolution nobody is ready for. Reproductive Biology and Endocrinology, 12(1), 63. https:// doi.org/10.1186/1477-7827-12-63.

Greil, A. L., Porter, K. L., Leitko, T. A., \& Riscilli, C. (1989). Why me? Theodicies of infertile women and men. Sociology of Health \& Illness, 11(3), 213-229.

Guest, G., Bunce, A., \& Johnson, L. (2006). How many interviews are enough? An experiment with data saturation and variability. Field Methods, 18(1), 59-82. https://doi.org/10.1177/1525822X05279903.

Inhorn, M. C. (2006). "He won't be my son": Middle Eastern Muslim men's discourses of adoption and gamete donation. Medical Anthropology Quarterly, 20(1), 94-120. https://doi.org/10.1525/maq.2006. 20.1.94.

Isikoglu, M., Senol, Y., Berkkanoglu, M., Ozgur, K., Donmez, L., \& Stones-Abbasi, A. (2006). Public opinion regarding oocyte donation in Turkey: First data from a secular population among the Islamic world. Human Reproduction, 21(1), 318-323. https://doi.org/10.1093/humrep/dei274.

Klein, J. U. (2013). Religious views: The Impact of traditional theological opinion on the practice of thirdparty reproduction. In M. Sauer (Ed.), Principles of Oocyte and Embryo Donation (pp. 383-394). London: Springer.

Klitzman, R. (2016a). How old is too old? Challenges faced by clinicians concerning age cutoffs for patients undergoing in vitro fertilization. Fertility and Sterility, 106(1), 216-224. https://doi.org/10.1016/j. fertnstert.2016.03.030.

Klitzman, R. (2016b). Reducing the number of fetuses in a pregnancy: Ethical and other challenges. Human Reproduction. https://doi.org/10.1093/humrep/dew231. (First published online: 6 October, 2016).

Klitzman, R. (2016c). Deciding how many embryos to transfer: Ongoing challenges and dilemmas. Reprod Biomed Online, 3, 1-15. https://doi.org/10.1016/j.rbms.2016.07.001.

Klitzman, R. (2016d). Buying and selling human eggs: Infertility providers' ethical and other concerns regarding egg donor agencies. BMC Medical Ethics, 17(1), 71. https://doi.org/10.1186/s12910-0160151-z. (Published online 8 Nov 2016).

Klitzman, R. (2016e). Struggles in defining and addressing requests for "family balancing": Ethical issues faced by providers and patients. Journal of Law, Medicine and Ethics, 44(4), 616-629. https://doi.org/ $10.1177 / 1073110516684804$

Klitzman, R. (2016f). Unconventional combinations of prospective parents: Ethical challenges faced by IVF providers. BMC Med Ethics, 18(1), 18. https://doi.org/10.1186/s12910-017-0177-x.

Klitzman, R. (2017). How much is a child worth? Providers' and patients' views and responses concerning ethical and policy challenges in paying for ART. PLoS One, 12(2), e0171939. https://doi.org/10.1371/ journal.pone.0171939. (eCollection 2017).

Lawrence, R., Rasinski, K., Yoon, J., \& Curlin, F. (2011). Obstetrician-gynecologists' views on contraception and natural family planning: A national survey. American Journal of Obstetrics and Gynecology, 204(2), 124-e1-124-e7. https://doi.org/10.1016/j.ajog.2010.08.051.

Marina, S., Marina, D., Marina, F., Fosas, N., Galiana, N., \& Jové, I. (2010). Sharing motherhood: Biological lesbian co-mothers, a new IVF indication. Human Reproduction, 25(4), 938-941. https://doi. org/10.1093/humrep/deq008.

Miller, A., Ziad-Miller, A., \& Elamin, E. M. (2014). Brain death and Islam: The interface of religion, culture, history, law, and modern medicine. CHEST Journal, 146(4), 1092-1101. https://doi.org/10. 1378/chest.14-0130.

Park, C. L. (2005). Religion as a meaning-making framework in coping with life stress. Journal of Social Issues, 61(4), 707-729. https://doi.org/10.1111/j.1540-4560.2005.00428.x.

Peterson, B., Gold, L., \& Feingold, T. (2007). The experience and influence of infertility: Considerations for couple counselors. The Family Journal, 15(3), 251-257. https://doi.org/10.1177/1066480707301365.

Ramondetta, L., Brown, A., Richardson, G., Urbauer, D., Thaker, P. H., Koenig, H. G., et al. (2011). Religious and spiritual beliefs of gynecologic oncologists may influence medical decision making. 
International Journal of Gynecological Cancer, 21(3), 573-581. https://doi.org/10.1097/IGC. 0b013e31820ba507.

RESOLVE. (2016). What are my chances of success with IVF?, http://www.resolve.org/family-buildingoptions/ivf-art/what-are-my-chances-of-success-with-ivf.html. Accessed September 5, 2017.

Roudsari, R. L., Allan, H. T., \& Smith, P. A. (2007). Looking at infertility through the lens of religion and spirituality: A review of the literature. Human Fertility (Cambridge, England), 10(3), 141-149. https:// doi.org/10.1080/14647270601182677.

Schenker, J. G. (2005). Assisted reproduction practice: Religious perspectives. Reproductive Biomedicine Online, 10(3), 310-319.

Sewpaul, V. (1999). Culture religion and infertility: A South African perspective. British Journal of Social Work, 29(5), 741-754.

Speier, A. (2011). Brokers, consumers and the internet: How North American consumers navigate their infertility journeys. Reproductive Biomedicine Online, 23(5), 592-599. https://doi.org/10.1016/j.rbmo. 2011.07.005.

Strauss, A., \& Corbin, J. (1990). Basics of qualitative research. Newbury Park, CA: Sage Publications.

Williams, R. S., Doody, K. J., Schattman, G. L., \& Adashi, E. Y. (2015). Public reporting of assisted reproductive technology outcomes: Past, present, and future. American Journal of Obstetrics and Gynecology, 212(2), 157-162. https://doi.org/10.1016/j.ajog.2014.05.010. 